\title{
Efficiency of Ibandronate in Monotherapy and in Combination with Alfacalcidol in Women with Postmenopausal Osteoporosis
}

\author{
S.I. Ismailov, $\mathrm{PhD}, \mathrm{ScD} *$; L.S. Abboskhuzhaeva; N.M. Alikhanova; G.I. Allayarova \\ Republican Specialized Scientific-Practical Medical Center of Endocrinology \\ of the Ministry of Public Health of the Republic of Uzbekistan, Tashkent, Uzbekistan
}

\begin{abstract}
The aim of this study was to carry out a comparative analysis of the efficiency of ibandronate monotherapy and combined therapies with ibandronate and alfacalcidol in women with postmenopausal osteoporosis.

Materials and Methods: A total of 53 women (mean age 60.7 years) with postmenopausal osteoporosis (PMO) were randomized to monotherapy with ibandronate $150 \mathrm{mg} / \mathrm{month}$ (Group Ib) $(\mathrm{n}=25)$ and therapy with ibandronate $150 \mathrm{mg} / \mathrm{month}$ plus alpha- $\mathrm{D}_{3}(\mathrm{AD} 3) 1 \mu \mathrm{g}$ (alfacalcidol) daily (Group Ib+AD3) $(\mathrm{n}=28)$. All women received calcium and vitamin $\mathrm{D}_{3}$ supplements. Patients were recruited in one center and were followed up for 6 months on a monthly basis. To assess the efficacy of therapy, BMD was measured at LS (L1-L4) and PF at the beginning and end of therapy by DEXA. Biochemical markers of bone turnover were also assessed.

Results: Statistically significant increases in BMD compared with baseline values and the control group were observed in both ibandronate treatment groups. Growth of BMD was significantly higher in Group $\mathrm{Ib}+\mathrm{AD} 3$ compared to Group $\mathrm{Ib}$. An assessment of CTX dynamics showed a notable decrease in CTX level in patients of both groups compared with levels before treatment. Generally, PTH level decreased insignificantly, but a more pronounced reduction was seen in Group Ib+AD3. TP1NP level significantly increased in Group Ib and was more pronounced in Group Ib+AD3.

Conclusion: Combined therapy with ibandronate sodium and the D-hormone analog alfacalcidol augments the effectiveness of treatment observed in ibandronate sodium monotherapy in PMO women. (Int J Biomed. 2016;6(3):190-194.).
\end{abstract}

Key Words: menopause • osteoporosis • bone mineral density • ibandronate treatment

\section{Abbreviations}

BMD, bone mineral density; LS, lumbar spine; PTH, parathyroid hormone; PF, proximal femur; BTMs, bone turnover markers; CTX, C-terminal telopeptide; TP1NP, type 1 procollagen total N-terminal propeptide.

\section{Introduction}

Postmenopausal osteoporosis (PMO) is one of the most important problems of modern health care because of the high prevalence and severity of fractures arising from minor injuries. The medical and social importance of osteoporotic fractures can be seen in the physical disability and increased mortality of patients. ${ }^{[1-4]}$

*Corresponding author: Prof. Said I. Ismailov, PhD, ScD. Director of Republican Specialized Scientific-Practical Medical Center of Endocrinology, Tashkent, Uzbekistan.

E-mail: ismailov.said@,list.ru
One of the main antiosteoporotic drugs used currently in the EU countries and the USA, are the bisphosphonates. In numerous randomized clinical trials, drugs of this group, more than others, prevented occurrence of new and recurrent fractures. ${ }^{[5-11]}$

Representatives of bisphosphonates improve prognosis of fractures due to their ability to significantly slow down the intensity of resorptive processes in bones, to affect bone remodeling, and to increase bone mineral density. Nitrogencontaining bisphosphonates of third generation ibandronic acid (Bonviva ${ }^{\circledR}$ ) possess promising features for clinical practice. Ibandronate has a unique structure, which has allowed combining a high affinity for bone tissue with a 
powerful antiresorptive potential. ${ }^{[12-14]}$

The clinical efficacy of ibandronate was confirmed by results of multicenter studies. Thus, the results of a multicenter, randomized, double-blind comparative study MOBILE (Monthly Orali Bandronate In Ladi Es) of therapy with ibandronate demonstrate a reduction in the incidence of vertebral fractures (by $4.9 \%$ and $6.6 \%$, respectively) and fractures of the thigh bone (by 3,2\% and 6,2\% respectively) after 1 and 2 years. ${ }^{[15-16]}$ The BONE study (Oral Ibandronate Osteoporosis Vertebral Fracture Trialin North America and Europe) found that women taking ibandronate on a daily or monthly basis have reduced risk of vertebral fractures and nonvertebral fractures in two populations - North America (60 and $54 \%$, respectively) and Europe (50 and 48\%, respectively). ${ }^{[17]}$

The aim of this study was to carry out a comparative analysis of the efficiency of ibandronate monotherapy and combined therapies with ibandronate and alfacalcidol in PMO women.

\section{Materials and Methods}

The study included 53 PMO women aged between 51 and 75 years (mean age $60.7 \pm 6.13$ years, median 61.0 years; interquartile range [IQR] 55.0-64.0 years) with PMO and menopause duration of at least 1 year. Osteoporosis was diagnosed according to WHO criteria (1994) using T score standard deviations (SDs) from the normative values of peak bone mass in healthy women. A value of not more than -1 SD was regarded as normal, a value of -1 to-2.5 SD as osteopenia, and $\leq-2.5 \mathrm{SD}$ as osteoporosis. Women were randomized to monotherapy with ibandronate $150 \mathrm{mg} / \mathrm{month}$ (Group $\mathrm{Ib}$ ) $(\mathrm{n}=25)$ and therapy with ibandronate $150 \mathrm{mg} / \mathrm{month}$ plus alpha$\mathrm{D}_{3}(\mathrm{AD} 3) 1 \mu \mathrm{g}$ (alfacalcidol) daily (Group Ib+AD3) $(\mathrm{n}=28)$. Both groups were homogeneous, particularly for BMD. All patients were informed about the disease and its complications and gave informed consent to participate in the study. All women received calcium supplements at a dose of $1,000 \mathrm{mg}$ and vitamin $\mathrm{D}_{3} 800 \mathrm{IU} /$ day. A control group of 16 women received only calcium 1,000 mg and vitamin D3 $800 \mathrm{IU} /$ day.

Physical load enhancement in the form of daily 30min walking was recommended to all patients. Patients were recruited in one center and were followed up for 6 months on a monthly basis. Women with diseases affecting bone metabolism such as hyperparathyroidism, thyrotoxicosis, Cushing's syndrome and disease, hypogonadism, malabsorption syndrome, kidney and liver disease, and malignancies were excluded, as were those taking medications that affect calcium metabolism during 12 months before the study.

\section{BMD Measurements}

The primary objective of the study was to assess the evolution of BMD on the background of the therapy, and the second objective was to follow the evolution of BTMs. To assess the efficacy of therapy, BMD was measured at LS (L1L4) and PF at the beginning and end of therapy by dual energy $\mathrm{x}$-ray absorptiometry (DEXA) using a bone densitometer (Prodigy, CE Lunar Corporation, USA) in private clinic "Doctor Summit" (Summit Trading Company, Ltd., Tashkent, Uzbekistan). In compliance with WHO criteria, BMD was expressed as $\mathrm{g} / \mathrm{cm}^{2}$ and T-score. Efficacy analyses were conducted according to the intention-to-treat (ITT) principle. The ITT population included all randomized patients who had taken at least one dose of treatment and who had a baseline and one post-baseline evaluation.

\section{Biochemical Measurements}

To assess the metabolic activity of bone remodeling, biochemical markers such as CTX (b-CrossLaps test) and TP1NP were measured by electrochemiluminescence assays (Elecsys biochemical analyzer, Elecsys b-CrossLaps) at baseline and after 6 months of therapy. An absorptiometric method was used to determine serum total calcium and nonorganic phosphorous, and a kinetic method was used to determine alkaline phosphatase activity by the amount of liberated 4-nitrophenol. Commercially available kits (CIS Bio International, France) were used to measure levels of parathyroid hormone (PTH).

The study was approved by the local Ethics Committee. Written informed consent was obtained from each patient.

Statistical analysis was performed using the statistical software «Statistica». (v6.0, StatSoft, USA). Baseline characteristics were summarized as frequencies and percentages for categorical variables and as mean \pm SD for continuous variables. The data for variation indices with nonparametric distribution are presented with medians and interquartile range [IQR] The Mann-Whitney (U Test) was used to compare the differences between groups. Group comparisons with respect to categorical variables are performed using chi-square test with Yates correction. A probability value of $P<0.05$ was considered statistically significant.

\section{Results}

The studied groups were comparable in terms of medical history (Table 1). High BMI was observed in all groups, which is likely associated with a sedentary lifestyle and poor diet (prevalence of pastry, fried food with use of animal fats) among postmenopausal women.

\section{Table 1.}

\section{Baseline characteristics of patients}

\begin{tabular}{|c|c|c|c|}
\hline \multirow[t]{2}{*}{ Variable } & \multicolumn{3}{|c|}{ Treatment } \\
\hline & $\begin{array}{c}\text { Control } \\
\text { group } \\
(\mathrm{n}=16)\end{array}$ & $\begin{array}{c}\text { Group Ib } \\
(\mathrm{n}=25)\end{array}$ & $\begin{array}{c}\text { Group } \\
\text { Ib+AD3) } \\
(\mathrm{n}=28)\end{array}$ \\
\hline Age,y & $62.9 \pm 6.4$ & $65.7 \pm 3.8$ & $61.1 \pm 1.35$ \\
\hline BMI, $\mathrm{kg} / \mathrm{m}^{2}$ & $31.2 \pm 4.8$ & $29.1 \pm 4.4$ & $32.7 \pm 0.50$ \\
\hline Menopause age, y & $50.5 \pm 3.6$ & $48.9 \pm 4.7$ & $46.8 \pm 2.00$ \\
\hline Menopause duration, $\mathrm{y}$ & $12.4 \pm 4.3$ & $16.8 \pm 5.9$ & $14.4 \pm 3.08$ \\
\hline $\begin{array}{l}\text { Fractures in anamnesis, } \mathrm{n}(\%) \\
\text { Hip } \\
\text { Wrist } \\
\text { Spine } \\
\text { Humerus }\end{array}$ & $\begin{array}{l}1(6.3) \\
1(6.3)\end{array}$ & $1(4.0)$ & $\begin{array}{l}1(3.6) \\
1(3.6)\end{array}$ \\
\hline Fractures in relatives, $\mathrm{n}(\%)$ & $2(12.5)$ & $2(8.0)$ & $3(10.7)$ \\
\hline Menopause before $45 \mathrm{yrs}, \mathrm{n}(\%)$ & $1(6.3)$ & $3(12.0)$ & $5(17.9)$ \\
\hline
\end{tabular}


Patients who had previous fractures were 2 women in Group Ib (fractures of wrist and humerus), 3 women in Group $\mathrm{Ib}+\mathrm{AD} 3$ (hip, vertebra, and humerus), and 2 women in the control group (hip and wrist). Patients who had a family history of fractures were $2(8.0 \%$ women in Group $\mathrm{Ib}$, $3(10.7 \%)$ women in Group Ib+AD3, and $2(12.5 \%)$ women in the control group. Onset of menopause before the age of 45 years had occurred in $3(12.0 \%), 5(17.9 \%)$ and $1(6.3 \%)$ women of Group Ib, Group Ib+AD3 and the control group, respectively.

Basal LS-BMD and PF-BMD equaled to $0.746 \pm 0.05 \mathrm{~g} /$ $\mathrm{cm}^{2}$ (median of $0.741 \mathrm{~g} / \mathrm{cm}^{2}$; IQR 0.709-0.781) and $0.747 \pm 0.05$ $\mathrm{g} / \mathrm{cm}^{2}$ (median of $0.746 \mathrm{~g} / \mathrm{cm}^{2}$; IQR $0.728-0.774$ ), respectively. Bone Mineral Density

An insignificant increase in BMD was noted in the group of women who used calcium supplements and vitamin D3. In this group, LS-BMD decreased in $8(50 \%)$ women and increased only in $4(25 \%)$ women. The average growth of BMD amounted to $0.24 \%$ (Fig.1). In the control group, PFBMD did not change in $8(50.0 \%)$ patients and an insignificant increase was seen in $7(43.8 \%)$. The average growth amounted to $0.06 \%$ (Fig.2).

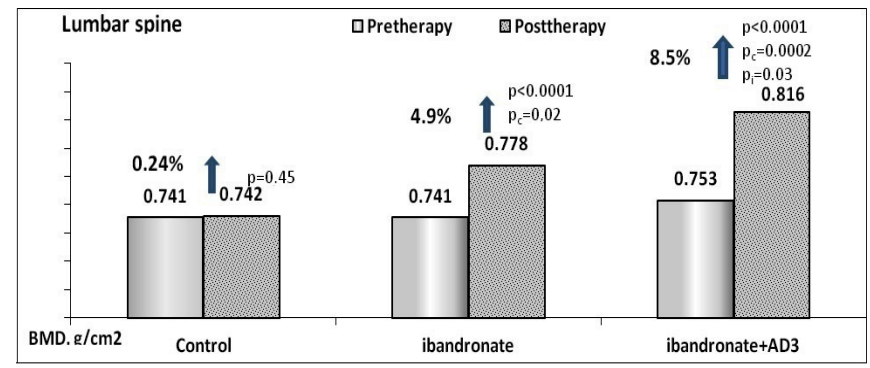

Fig. 1. BMD-LS at the beginning and end of 6-month therapy (DEXA results).

$p$-compared to the parameter before therapy,

$p_{c}$-compared to the control group, $p_{i}$-compared to the ibandronate group after therapy.

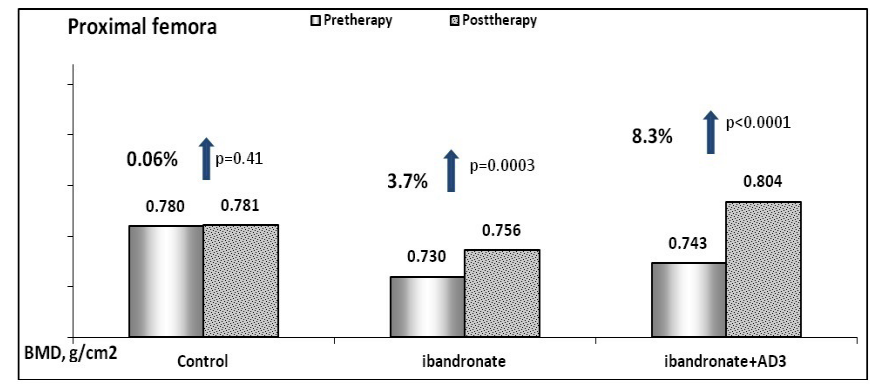

Fig. 2. BMD-PF at the beginning and end of 6-month therapy (DEXA results).

\section{$p$-compared to the parameter before therapy}

In Group $\mathrm{Ib}$, a significant increase in LS-BMD and PFBMD was found. However, we observed a decrease in LS- and PF-BMD in $3(12.0 \%)$ and $4(16.0 \%)$, respectively. Growth of BMD was significantly higher in Group Ib+AD3 compared to Group Ib and the control group; a slight decrease in LS-BMD was seen in 2 patients of Group Ib+AD3.

\section{Biochemical Markers of Bone Turnover}

An assessment of CTX dynamics showed a notable decrease in CTX level in patients of both groups compared with levels before treatment (Fig.3). Generally, PTH level decreased insignificantly, but a more pronounced reduction was seen in Group Ib+AD3. TP1NP level significantly increased in Group $\mathrm{Ib}(30.2 \%)$ and was more pronounced in Group Ib+AD3 (52.2\%).
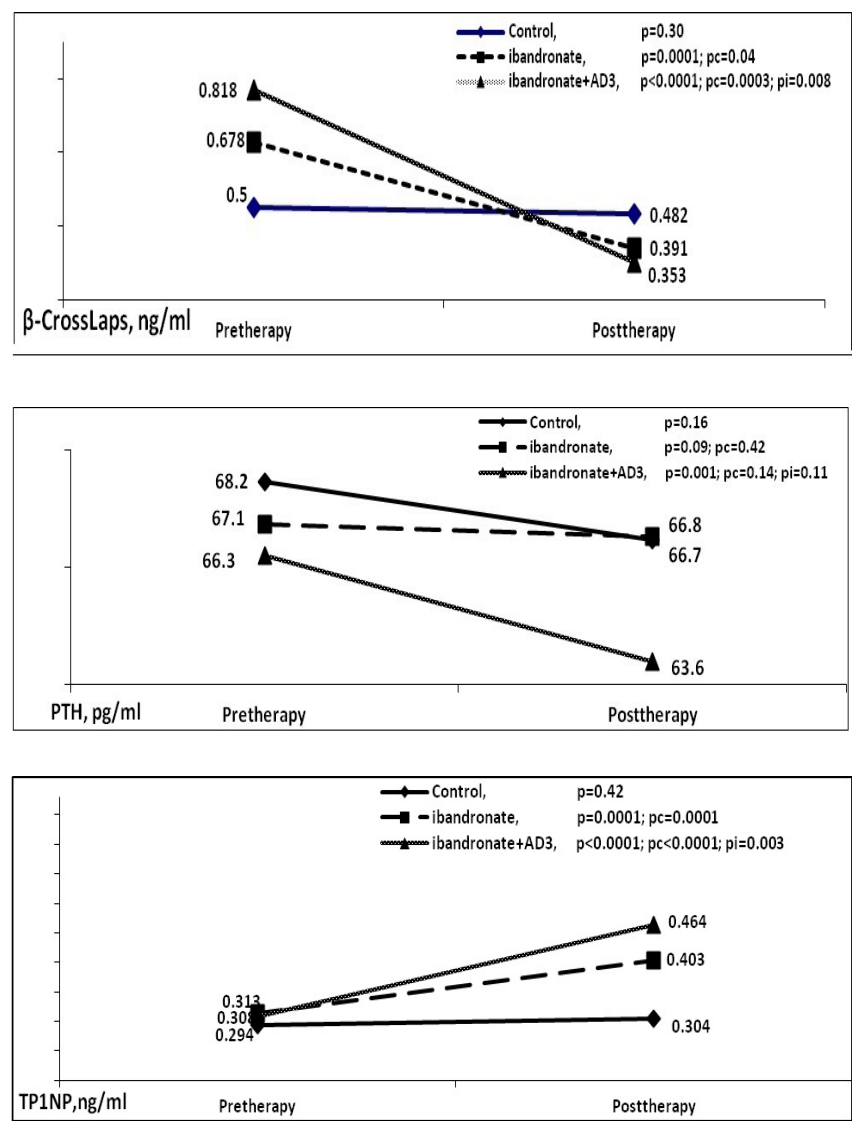

Fig. 3. Serum markers of bone turnover

$p$ - compared to the parameter before therapy, $p_{c}$-compared to the control,

$p_{i}{ }_{i}$-compared to the ibandronate group after therapy

Laboratory investigations demonstrated normal parameters for calcium-phosphorus metabolism (Ca, P and alkaline phosphatase) in all groups without significant intergroup differences. Levels of calcium and phosphorus as well as alkaline phosphatase activity were in the reference limits, not changing significantly in both groups.

\section{$\underline{\text { Safety }}$}

A flu-like syndrome was observed in 9 women (4 patients in Group $\mathrm{Ib}$ and 5 patients in Group Ib+AD3) during study. The intensity of the syndrome was light to moderate, resolved spontaneously or after administration of antipyretics, and did not require discontinuation of therapy.

\section{Discussion}

Currently, ibandronate is one of the most in-demand drugs with proven ability to reduce the risk of vertebral 
fractures and a dose-dependent activity in relation to peripheral fractures. Ibandronate has been studied in clinical trials involving nearly 9,000 patients. The results of evaluation of ibandronate efficacy in osteoporosis were reported in large randomized studies: BONE, ${ }^{[17]}$ MOPS,${ }^{[18]}$ MOBILE. ${ }^{[15]}$

In BONE study, both daily and monthly administration of ibandronate led to a significant increase of vertebral BMD (to 5.4 and $4.4 \%$ - North American population, and to 7.1 and $6.3 \%$ - European population) compared to its baseline values. Growth of PF-BMD by $2.6 \%$ and $3.7 \%$ was seen with daily intake and by $2.5 \%$ and $3.1 \%$ with monthly intake for North American and European populations of patients. ${ }^{[17]}$ During a 2-year (MOBILE study), LS-BMD of patients receiving ibandronate $150 \mathrm{mg}$ once monthly increased by $7.6 \%$ (from baseline), and it increased by $6.4 \%$ from baseline in patients receiving $100 \mathrm{mg}$ per month. After 3 years of treatment, patients in both groups showed an increase in PF-BMD as compared with the original mineral density $(3.4 \%-100 \mathrm{mg}$ and $4.1 \%-150 \mathrm{mg}) \cdot{ }^{[15]}$

In our study, within 6 months PMO women received ibandronate $150 \mathrm{mg}$ once monthly, as well as the same dose of ibandronate plus Alpha-D3 1mg/day. Significant improvements of LS-BMD by $4.9 \%$ and PF-BMD by $3.7 \%$ were observed on the background of ibandronate monotherapy. In combination therapy of ibandronate with Alpha-D3, an increase in LSBMD and PF-BMD comprised $8.5 \%$ and $8.3 \%$, respectively. A decrease in LS-BMD and PF-BMD was seen in 3 and 4 women, respectively, in Group $\mathrm{Ib}$. At the same time, only 2 patients treated with $\mathrm{Ib}+\mathrm{AD} 3$ demonstrated a slight decrease in LS-BMD.

Two opposed processes, bone formation and bone resorption, characterize bone metabolism. The type 1 collagen degradation product CTX is a parameter characterizing the degree of bone tissue resorption, while TP1NP is a marker of bone matrix formation. Increases in CTX are believed to be the primary and most sensitive parameter of the shift in balance from bone remodeling towards bone resorption. ${ }^{[19]}$

Study of markers of bone metabolism showed that CTX level decreased significantly in the treatment with ibandronate, and an even greater reduction resulted from the combination therapy. Effects of ibandronate were also associated with a significant increase in TP1NP level, more pronounced in Group Ib+AD3.

Bisphosphonates reduce the number and activity of osteoclasts, induce their apoptosis and inhibit enzymes of the mevalonate pathway, which ultimately results in reduced bone resorption. However, D-hormone deficiency may prevent the bisphosphonates from exerting their antiresorptive effects. D-hormone deficiency may arise from impaired vitamin D conversion into D-hormone and from primary (nutritional) shortage of calcium and vitamin D. As compared with bisphosphonates, active metabolites of vitamin D posses more diverse actions, which have a complementary effect: they reduce osteoclast genesis, stimulate differentiation of preosteoblasts and bone formation (anabolic effect), and also have metabolic effects that appear as reduced levels of PTH and pro-inflammatory cytokines. ${ }^{[20]}$ The addition of alfacalcidol to the bisphosphonates may not only contribute to the effectiveness of therapy, but can also solve such a clinical problem as resistance to bisphosphonates, which sometimes is as high as $83 \%{ }^{[21]}$

PTH is a key regulator of calcium-phosphorus metabolism. It is synthesized by the parathyroid glands in response to a reduction in extracellular calcium concentrations, and it activates osteoclasts to increase bone resorption resorption (demineralization, bone destruction); as a result, calcium and phosphorus are released into the circulation. Increases in PTH levels, particularly in elderly individuals with vitamin D3 deficiency, can result in osteomalacia, increased bone remodeling, bone mass reduction, and fractures. ${ }^{[22]}$ Reduction of PTH levels in our study was observed in both treatment groups with more significant reduction in combined therapy.

\section{Conclusion}

Thus, combined therapy with ibandronate sodium and the D-hormone analog alfacalcidol augments the effectiveness of treatment observed in ibandronate sodium monotherapy in PMO women.

\section{Sources of Funding}

This study was conducted as an investigator driven study. However, F. Hoffmann-La Roche Ltd has funded the Republican Specialized Scientific-Practical Medical Center of Endocrinology to perform the study. F. Hoffmann-La Roche Ltd was not involved in the acquisition of the data, in the statistical analysis, or in the drafting and revision of the article.

\section{Competing interests}

The authors declare that they have no competing interests.

\section{References}

1. Zotkin $\mathrm{EG}_{2}$ Safonova YA. Clinical rationale for the use of ibandronate in the treatment of osteoporosis. Effective Pharmacotherapy (Endocrinology). 2011;2:28-32. [in Russian]. 2. Marchenkova LA., Prokhorova EA., Dreval' AV, et al. The influence of postmenopausal osteoporosis and subclinical vertebral fractures on postmenopausal women's quality of life. Almanac of Clinical Medicine 2014 32:43-49. [in Russian].

3. Popov AA, Izmozherova NV, Gavrilov EI, Fominykh MI. Assessing the impact of radial bone fractures on quality of life of residents of Yekaterinburg, suffering from postmenopausal osteoporosis. Osteoporosis and Osteopathy. 2007;3:9-11. [in Russian].

4. Reginster JY, Hiligsmann M, Rabenda V, et al. Ibandronate in the Management of Postmenopausal Osteoporosis. Clinical Medicine: Therapeutics 2009;1:1409-21.

5. Pyadushkina1 EA, Gerasimova KV, Goryainov SV, et al. Comparative pharmacoeconomic analysis of the use of ibandronate (Bonviva ${ }^{\circledR}$ ) to prevent fractures in postmenopausal osteoporosis. Modern Reumatology Journal 2012; 4:89-96. [in Russian].

6. Aslan A, Sargın S, Özmeriç A, Yağcı Ş. Treatments of 
patients with postmenopausal osteoporosis: a comparative study. OA Musculoskeletal Medicine 2014;2(1):1-7.

7. Bumbasirević M, Lesić A, Denić-Marković L, Zivković K; ORPHEUM Study Group. Prospective clinical study of once monthly ibandronate in the treatment of osteoporosis and prevention of fractures in postmenopausal women: ORPHEUM Study. Srp Arh Celok Lek 2011;139(11-12):790-4.

8. Chesnut CH 3rd, Skag A, Christiansen C, Recker R, Stakkestad JA, Hoiseth A, et al. Effects of oral ibandronate administered daily or intermittently on fracture risk in postmenopausal osteoporosis. J Bone Miner Res. 2004; 19:1241-9.

9. Miller PD1, Ward P, Pfister T, Leigh C, Body JJ. Renal tolerability of intermittent intravenous ibandronate treatment for patients with postmenopausal osteoporosis: a review. Clin Exp Rheumatol 2008;26:1125-33.

10. Stuss M, Sewerynek E, Król I, Stępień-Kłos W, Jędrzejczyk S. Assessment of OPG, RANKL, bone turnover markers serum levels and BMD after treatment with strontium ranelate and ibandronate in patients with postmenopausal osteoporosis. Endokrynologia Polska 2016;67(2):174-84.

11. Vujasinović-Stupar N, Milić N, Petrović-Rackov L, Prodanović N, Mijailović-Ivković M, Grujić Z, et al; ESTHER Study Group. Efficacy and safety of once monthly ibandronate treatment in patients with reduced bone mineral density ESTHER study. Srp Arh Celok Lek 2010;138(1-2):56-61.

12. Golovach IY. Treatment of osteoporosis in the context of prevention of fractures: implementation of evidencebased medicine in clinical practice. In sight - ibandronic acid. Trauma. 2013;14(1) http://www.mif-ua.com/archive/ article/35443 [in Ukrainian].

13. Dedukh NV. Osteoporosis: a mechanism of therapeutic action bisphosphonates and clinical perspectives. Trauma. 2013;14(2) http://www.mif-ua.com/archive/article/35950 [in Russian].

14. Papapoulos S. Ibandronate: a potent new bisphosphonate in the management of postmenopausl osteoporosis. Int J Clin Pract. 2003;57(5):417-22.

15. Miller PD, McClung MR, Macovei L, Stakkestad JA, Luckey M, Bonvoisin B, et al. Monthly oral ibandronate therapy in postmenopausal osteoporosis: 1-year results from the MOBILE Study. J Bone Miner Res 2005;20(8):1315-22.

16. Reginster JY, Adami S, Lakatos P, Greenwald M, Stepan JJ, Silverman SL, et al. Efficacy and tolerability of oncemonthly oral ibandronate in postmenopausal osteoporosis: 2 year results from the MOBILE study. Ann Rheum Dis 2006;65(5):654-61.

17. Chesnut CH, Ettinger MP, Miller PD, Baylink DJ, Emkey $\mathrm{R}$, Harris ST, et al. Ibandronate produces significant, similar antifracture efficacy in North American and European women: new clinical findings from BONE. Curr Med Res Opin. 2005. 21(3):391-401.

18. Reginster JY, Wilson KM, Dumont E, Bonvoisin B, Barrett $\mathrm{J}$. Monthly oral ibandronate is well tolerated and efficacious in postmenopausal women: results from the monthly oral pilot study. J Clin Endocrinol Metab. 2005; 90(9):5018-24.

19. Delmas PD, Eastell R, Garnero P, Seibel MJ, Stepan $\mathrm{J}$; Committee of Scientific Advisors of the International Osteoporosis Foundation. The use of biochemical markers of bone turnover in osteoporosis. Osteoporos Int. 2000; 11 Suppl $6:$ S2-17.

20. Belaya ZhE, Rozhinskaya LY. Vitamin D in the treatment of osteoporosis: its role in combination with drugs for the treatment of osteoporosis, extraskeletal effects. Effective pharmacotherapy (Endocrinology). 2013;2(38):14-29. [in Russian].

21. Ershova OB. Bisphosphonates in osteoporosis therapy. Focus on alendronate (in Russian). Russian Medical Journal 2008;16(24):1626-1628.

22. Kostyuchek DF, Dushenkova TA, Rischuk SV. Early diagnosis of osteoporosis in pre- and post-menopausal women. J Obstet Women Dis 2006;55(1):3-7. [in Russian]. 